\title{
BIOLOGICAL ACTIVITY OF PEPSTATINS, PEPSTANONE A AND PARTIAL PEPTIDES ON PEPSIN, CATHEPSIN D AND RENIN
}

\author{
Takanki Aoyagi, Hajime Morishima, Rinzo Nishizawa, \\ Setsuko Kunimoto, Tomio Takeuchi and Hamao Umezawa \\ Institute of Microbial Chemistry, Shinagawa-ku, Tokyo, Japan \\ HiRoh IKEZAwa \\ Faculty of Pharmaceutical Sciences, \\ Nagoya City University, Mizuho-ku, Nagoya, Japan
}

(Received for publication October 18, 1972)

The inhibition of pepsin, cathepsin D and renin by pepstatins, pepstanone $A$ and their partial peptides is descrijed. A new method using a nonapeptide containing ${ }^{3} \mathrm{H}-\mathrm{Val}$ as the substrate was devised for determination of renin activity. The pepstatin partial peptides valyl-valyl-4-amino-3-hydroxy-6-methylheptanoic acid (Val-Val-AHMHA), isovaleryl-valyl-valyl-4-amino-3-hydroxy-6methylheptanoic acid (IVA-Val-Val-AHMHA) and carbobenzoxyvalyl-valyl-4amino-3-hydroxy-6-methylheptanoic acid (Z-Val-Val-AHMHA) weakly inhibited proteolysis by pepsin and did not inhibit renin. Pepstatins $B, C, E$ and $G$ were as active as pepstatin $A$ against pepsin and were slightly more active against renin than pepstatin $A$. Pepstanone $A$ was as active as pepstatin $A$ against pepsin but slightly less active against renin.

As reported in previous papers ${ }^{1,2,3)}$, pepstatins $A, B, C, E$ and $G$, and pepstanone $A$ are produced by the pepstatin A-producing streptomyces. Pepstatin A has been shown to be a specific inhibitor of acid proteases and shows a strong protective effect against stomach ulcer in pylolusligated rats $^{4)}$. It also inhibits cathepsin $\mathrm{D}$, a pepsin-like acid protease $^{5)}$.

A new method was devised for the determination of renin activity. It is based on the cleavage of a nonapeptide, His-Pro-Phe-His-Leu-Leu- $\left({ }^{3} \mathrm{H}-\mathrm{Val}\right)-\mathrm{Ty}$-Ser by renin to yield a pentapeptide His-Pro-Phe-His-Leu and a tetrapeptide Leu- $\left({ }^{3} \mathrm{H}-\mathrm{Val}\right)$ Tyr-Ser. The latter is separated from the reaction mixture by Dowex $50-\mathrm{X} 8$ column chromatography and determined by a soft beta-counting spectrometer.

In this paper, the effects of pepstatins, pepstanone $A$ and partial peptides on pepsin, cathepsin $D$ and renin are reported.

\section{Materials and Methods}

Enzymes: Porcine pepsin (3,200 units/mg) was purchased from Sigma Chemical Co., U.S.A., and hog kidney renin (1 dog unit/mg) was purchased from General Biochemicals, U.S.A. Both were used without further purification. Porcine pepsin $(40 \mu \mathrm{g} / \mathrm{ml})$ was dissolved in $0.001 \mathrm{~N} \mathrm{HCl}$, and hog kidney renin $(1 \mathrm{mg} / \mathrm{ml})$ was dissolved immediately before use in $\mathrm{pH} \quad 7.5 \quad 0.05 \mathrm{M}$ phosphate buffer containing $0.5 \%$ polyvinylpyrrolidone (PVP). Cathepsin D was prepared from the acetone powder of lysosomal-mitochondrial pellets 
obtained from swine liver homogenate as described previously ${ }^{5}$.

Substrates: Casein was purified according to the procedure described by NoRMAN ${ }^{6)}$ and a $0.6 \%$ casein solution in $0.75 \%$ lactic acid was used as a pepsin substrate. Bovine hemoglobin was purchased from Nutritional Biochemical Co., U.S.A. and a $1 \%$ hemoglobin solution in $0.2 \mathrm{M}$ acetate buffer ( $\mathrm{pH}$ 3.2) was used as a substrate for cathepsin D. His-Pro-Phe-HisLeu-Leu-( ${ }^{3} \mathrm{H}-\mathrm{Val}$ )-Tyr-Ser (abbreviated as ${ }^{3} \mathrm{H}-\mathrm{Val}$-nonapeptide, $2.43 \times 10^{6} \mathrm{cpm} / \mathrm{mg}$ ) was synthesized by the method described below and a stock solution of ${ }^{3} \mathrm{H}-\mathrm{Val}$-nonapeptide was dissolved in $0.01 \mathrm{~N} \mathrm{HCl}$. This solution was adjusted carefully to $\mathrm{pH} 4.0$ by the addition of $0.5 \mathrm{~N} \mathrm{NaOH}$ and diluted to $0.6 \%$ concentration with water. The stock solution was diluted with $0.05 \mathrm{M}$ phosphate buffer, $\mathrm{pH} 7.5$, containing $0.05 \% \mathrm{PVP}$, to give the final concentration of $0.06 \%$.

Pepstatin A,B,C,E and G, and Pepstanone A: They were prepared from fermentation broths of Streptomyces testaceus as described in previous papers ${ }^{1,3)}$. Their structures are described later.

Synthesis of partial peptides of pepstatin: AHMHA (4-amino-3-hydroxy-6-methylheptanoic acid) used for synthesis was obtained by hydrolysis of pepstatin A. All amino acids used had the L-configuration.

Ala-AHMHA: Carbobenzoxyalanine (Z-Ala) and AHMHA were coupled by an active ester method. Succinimide ester of carbobenzoxyalanine was prepared by the method of ANDERSON et $a l^{7)}$, and the protective group was removed by catalytic hydrogenation. m.p. $194 \sim 195^{\circ} \mathrm{C}$ (dec.), $[\alpha]_{\mathrm{D}}^{23}-43.0^{\circ}$ (c 1, water). Anal. Calcd. for $\mathrm{C}_{11} \mathrm{H}_{22} \mathrm{~N}_{2} \mathrm{O}_{4}: \mathrm{C} 53.64, \mathrm{H}$ 9.00, N 11.37. Found: C 53.05, H 8.89, N 10.90.

IVA-Val-Val: Carbobenzoxyvaline ( $\mathrm{Z}-\mathrm{Val})$ and methyl ester of valine were coupled by the dicyclohexylcarbodiimide (DCC) method, and valylvaline (Val-Val) was obtained by alkaline saponification followed by catalytic hydrogenation. Isovaleryl-valyl-valine (IVA$\mathrm{Val}-\mathrm{Val}$ ) was prepared from $\mathrm{Val}-\mathrm{Val}$ and isovaleryl chloride by the Shotten-BaumanN reaction. m.p. $142 \sim 143.5^{\circ} \mathrm{C},[\alpha]_{\mathrm{D}}^{22}-38.4^{\circ}$ (c 1, methanol). Anal. Calcd. for $\mathrm{C}_{15} \mathrm{H}_{28} \mathrm{~N}_{2} \mathrm{O}_{4}$ : C 59.97, H 9.40, N 9.33. Found: C 59.79, H 9.14, N 9.40.

IVA-Val-Val-AHMHA: The synthesis was described in a previous paper ${ }^{8)}$.

Val-AHMHA: Z-Val was condensed with the $p$-nitrobenzyl ester of 4-amino-3hydroxy-6-methylheptanoic acid $p^{\text {-toluensulfonate }}{ }^{8)}$ in the presence of one equivalent of triethylamine by a mixed anhydride method, and from the reaction product, Val-AHMHA monohydrate was obtained by catalytic hydrogenation. $[\alpha]_{\mathrm{D}}^{25}+13.0^{\circ}(c 0.92$, water). Anal. Caicd. for $\mathrm{C}_{13} \mathrm{H}_{26} \mathrm{~N}_{2} \mathrm{O}_{4} \cdot \mathrm{H}_{2} \mathrm{O}$ : C 53.40, $\mathrm{H}$ 9.65, N 9.58. Found: C 53.42, $\mathrm{H} \mathrm{9.50,} \mathrm{N} \mathrm{9.24.}$

Z-Val-Val-AHMHA : This compound was prepared by reaction of succinimide ester of carbobenzoxyvaline with Val-AHMHA monohydrate in aqueous dioxane: 'm.p. 199.5 $200^{\circ} \mathrm{C},[\alpha]_{\mathrm{D}}^{22}-47.9^{\circ}$ (c 1.3, acetic acid). Anal. Calcd. for $\mathrm{C}_{26} \mathrm{H}_{42} \mathrm{~N}_{3} \mathrm{O}_{7}$ : C $61.39, \mathrm{H} 8.32, \mathrm{~N}$ 8.26. Found: $\mathrm{C} 61.19, \mathrm{H} 8.02, \mathrm{~N} 8.27$.

Val-Val-AHMHA: This compound was obtained from Z-Val-Val-AHMHA by catalytic hydrogenation. $[\alpha]_{\mathrm{D}}^{20}-27.7^{\circ}$ (c 0.65 , water). Anal. Calcd. for $\mathrm{C}_{18} \mathrm{H}_{35} \mathrm{~N}_{3} \mathrm{O}_{5}:$ C 57.88 , H 9.45, N 11.25. Found: C 57.44, H 9.28, N 10.81.

Synthesis of His-Pro-Phe-His-Leu-Leu- $\left({ }^{3} \mathrm{H}-\mathrm{Val}\right)-\mathrm{Tyr}-\mathrm{Ser}$ : All amino acids used had the L-configuration. The synthesis of the protected nonapeptide-resin was carried out according to the usual solid phase procedure ${ }^{9)}$ starting from Boc-Ser $\left(\mathrm{Bz}_{\mathrm{z}}\right)$-resin $(4.0 \mathrm{~g} ; 0.40$ mmole of ser/g, Boc; tert-butyloxycarbonyl, Bz; benzyl). Each Boc-amino acid to be added was used in 3-fold excess. The extra functional groups of Boc-Tyr and -His were protected with benzyl and tosyl, respectively. DCC was used for coupling (3-fold excess). Boc-groups were removed with $1 \mathrm{~N} \mathrm{HCl}$ in acetic acid. Boc- ${ }^{3} \mathrm{H}-\mathrm{Val}$ was prepared from the reaction of tert-butyl azidoformate and ${ }^{3} \mathrm{H}-\mathrm{Val}$ (purchased from New England Nuclear Corporation) with $\mathrm{Val}(0.234 \mathrm{~g})$ as a carrier in the usual method. After Boc- ${ }^{3} \mathrm{H}-\mathrm{Val}$ was coupled to the dipeptide-resin followed by successive washing with dichloromethane, ethanol and dichloromethane, the resin was allowed to react with Boc-Val in the usual manner ${ }^{10)}$. The rest 
of the synthetic sequence was then carried out. The yield of the protected nonapeptideresin was $5.63 \mathrm{~g}$. Cleavage of the protected nonapeptide from the resin $(5.60 \mathrm{~g})$ together with removal of all protecting groups was achieved in one step by treatment with anhydrous $\mathrm{HF}$ in the presence of anisole for 60 minutes at $0^{\circ} \mathrm{C}$. The crude product was extracted with a large quantity of $1 \mathrm{~N}$ acetic acid and the extract was applied to an Amberlite CG-50 $\left(\mathrm{H}^{+}\right.$form, type 1$)$ column which was throughly washed with $2 \mathrm{~N}$ acetic acid. The product was eluted with $90 \%$ acetic acid and the eluate was lyophilized. The nonapeptide diacetate weighed $0.597 \mathrm{~g} ; \mathrm{m} . \mathrm{p} .203^{\circ} \mathrm{C}$ (dec.); $[\alpha]_{\mathrm{D}}^{29}-39.8^{\circ}$ (c 0.5 , acetic acid); radioactivity $2.43 \times 10^{6} \mathrm{cpm} / \mathrm{mg}$. On paper electrophoresis $(25 \mathrm{~V} / \mathrm{cm}$ for 50 minutes, $0.2 \mathrm{M}$ pyridine-acetic acid, $\mathrm{pH} 4.8$ ), the peptide was homogeneous, moving to the cathode with an $\mathrm{Rm}$ value of 0.63 compared to L-histidine as 1.0. On thin-layer chromatography using Silica Gel G (E. Merck), the peptide gave a single spot at Rf 0.61 with butanol-acetic acid-water-pyridine $(15: 3: 12: 10)$ compared to L-histidine with $\mathrm{Rf} 0.34$. Amino acid ratios were obtained by automatic ion-exchange chromatography of hydrolysates prepared by heating the peptides in $6 \mathrm{~N} \mathrm{HCl}$ at $110^{\circ} \mathrm{C}$ in evacuated tubes for 48 hours: His, 1.89 ; Pro, 1.03; Phe, 1.05; Leu, 2.01; Val, 0.98; Tyr, 1.02; Ser, 1.00.

Reaction system for hydrolysis of casein by pepsin: One $\mathrm{ml}$ of $0.6 \%$ casein solution, $0.8 \mathrm{ml}$ of $0.02 \mathrm{M} \mathrm{KCl}-\mathrm{HCl}$ buffer $(\mathrm{pH} 2.0)$ and $0.1 \mathrm{ml}$ of the same buffer with or without an inhibitor were mixed and incubated for 3 minutes at $37^{\circ} \mathrm{C}$. Then, $0.1 \mathrm{ml}$ of a solution of porcine pepsin $(40 \mu \mathrm{g} / \mathrm{ml})$ was added. After incubation at $37^{\circ} \mathrm{C}$ for 30 minutes, $2.0 \mathrm{ml}$ of $1.7 \mathrm{M}$ perchloric acid (PCA) was added and the mixture was kept for 1 hour at room temperature. It was then centrifuged and the extinction of the acid-soluble fraction was read at $280 \mathrm{~m} \mu^{4}$.

Reaction system for hydrolysis of hemoglobin by cathepsin D: Three $\mathrm{ml}$ of $1.0 \%$ hemoglobin solution, $0.8 \mathrm{ml}$ of $0.05 \mathrm{M}$ acetate buffer $(\mathrm{pH} 3.2)$ with or without an inhibitor and $0.2 \mathrm{ml}$ of the enzyme solution (protein : $0.68 \sim 2.5 \mathrm{mg}$ ) were mixed. After incubation at $37^{\circ} \mathrm{C}$ for 30 minutes, $2.0 \mathrm{ml}$ of $9 \%$ trichloroacetic acid (TCA) was added and the mixture was kept for 30 minutes at $37^{\circ} \mathrm{C}$. The mixture was filtered and the extinction at $280 \mathrm{~m} \mu$ was measured as described above.

Reaction system for hydrolysis of ${ }^{3} \mathrm{H}-\mathrm{Val}$-nonapeptide by renin: The nonapeptide His-Pro-Phe-His-Leu-Leu- $\left({ }^{3} \mathrm{H}-\mathrm{Val}\right)-\mathrm{Try}-\mathrm{Ser}$ was used as the substrate. Five tenth $\mathrm{ml}$ of $0.06 \%{ }^{3} \mathrm{H}-\mathrm{Val}-$ nonapeptide, $0.3 \mathrm{ml}$ of $0.05 \mathrm{M}$ phosphate buffer, containing $0.05 \% \mathrm{PVP}$ $(\mathrm{pH} 7.5)$ and $0.1 \mathrm{ml}$ of the same buffer with or without an inhibitor were mixed and incubated for 3 minutes at $37^{\circ} \mathrm{C}$. Then, $0.1 \mathrm{ml}$ of a solution of hog kidney renin $(1 \mathrm{mg} / \mathrm{ml})$ was added. After incubation at $37^{\circ} \mathrm{C}$ for 60 minutes, the reaction mixture was put in a boiling water bath for 1 minute. Then, it was passed through a column of Dowex 50-X8 $\left(\mathrm{NH}_{4}{ }^{+}\right.$form, $200 \sim 400$ mesh, $\left.0.5 \times 5.0 \mathrm{~cm}\right)$ at room temperature and followed by $1 \mathrm{ml}$ of distilled water. The radioactivity of Leu-( $\left.{ }^{3} \mathrm{H}-\mathrm{Val}\right)-\mathrm{Ty}-\mathrm{Ser}$ in the eluate and the wash was determined in a Beckman Liquid Scintillation System LS-250 using $8 \mathrm{ml}$ of BRAY's scintillation solution ${ }^{11)}$. The reaction was also carried out in the reaction mixture containing boiled enzyme solution and the result was taken as the blank value.

Estimation of percent inhibition on proteolytic reactions: The percent inhibition of an enzymatic reaction was calculated from the experimental data obtained by the methods described above, and the probit of the percent inhibition was plotted against the logarithmic concentration of each inhibitor. The concentration of inhibitor required for $50 \%$ inhibition $\left(\mathrm{ID}_{50}\right)$ of enzyme activity was obtained from this plot as described in a previous peper ${ }^{4)}$ :

\section{Results and Discussion}

Pepstatin $A$ is a specific inhibitor of acid proteases ${ }^{1,4,12)}$ and the hydrophobicity of its structure seems to play an important role in binding of pepstatin to acid proteases. On the other hand, two hydroxyl groups of pepstatin are thought to be 
Fig. 1. Effect of the renin concentration on hydrolysis of ${ }^{3} \mathrm{H}-\mathrm{Val}$-nonapeptide

The indicated amounts of renin were incubated in the standard assay procedure.

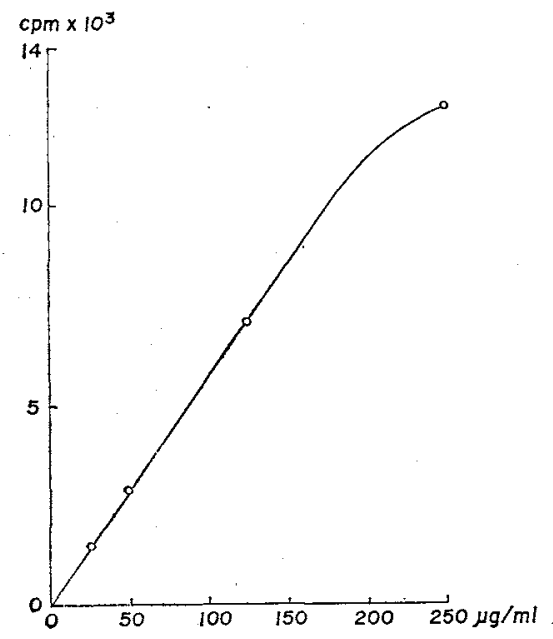

involved in the binding of pepstatin $\mathrm{A}$ with pepsin because dehydroacetyl pepstatin, in which the hydroxyl group of dehydropepstatin is acetylated, is 150 times less active than pepstatin. We have also suggested that the 4-amino-3-hydroxy-6-methylheptanoic acid (AHMHA) moiety in pepstatins and pepstanone is the most important moiety for binding with pepsin.

For the determination of renin activity, methods including biological assay ${ }^{13)}$, radiochemical assay ${ }^{14)}$ and an automatic chemical determination ${ }^{15)}$ have been reported. We established a new assay method of renin activity, using a ${ }^{3} \mathrm{H}$-Val-nonapeptide and counting the radioactivity of a reaction product.

The effect of the renin concentration on the hydrolysis of ${ }^{3} \mathrm{H}$-Val-nonapeptide was examined. The reaction rate was linear up to an enzyme concentration of $200 \mu \mathrm{g}$ (Fig. 1). The reaction rate was linear for 60 minutes but thereafter gradually slowed down (Fig. 2).

The effect of pepstatins, pepstanone $A$ and their partial peptides and ${ }^{3} \mathrm{H}-\mathrm{Val}-$ nonapeptide on hog kidney renin is shown in Table 1 . It is apparent from Table 1 that pepstatins strongly inhibit pepsin and renin. Against pepsin and renin, AHMHA, Ala-AHMHA, Val-AHMHA and IVA-Val-Val showed no inhibition even at the high concentration of $250 \mu \mathrm{g} / \mathrm{ml}$. However, as shown in the table, Val-Val-AHMHA, IVAVal-Val-AHMHA and Z-Val-Val-AHMHA weakly inhibited proteolysis by pepsin. The results suggest that an increase of hydrophobic property may enhance the inhibition.

The structure of pepstatin A,B,C,D,E, F, G and H, and pepstanone A are as follows: 


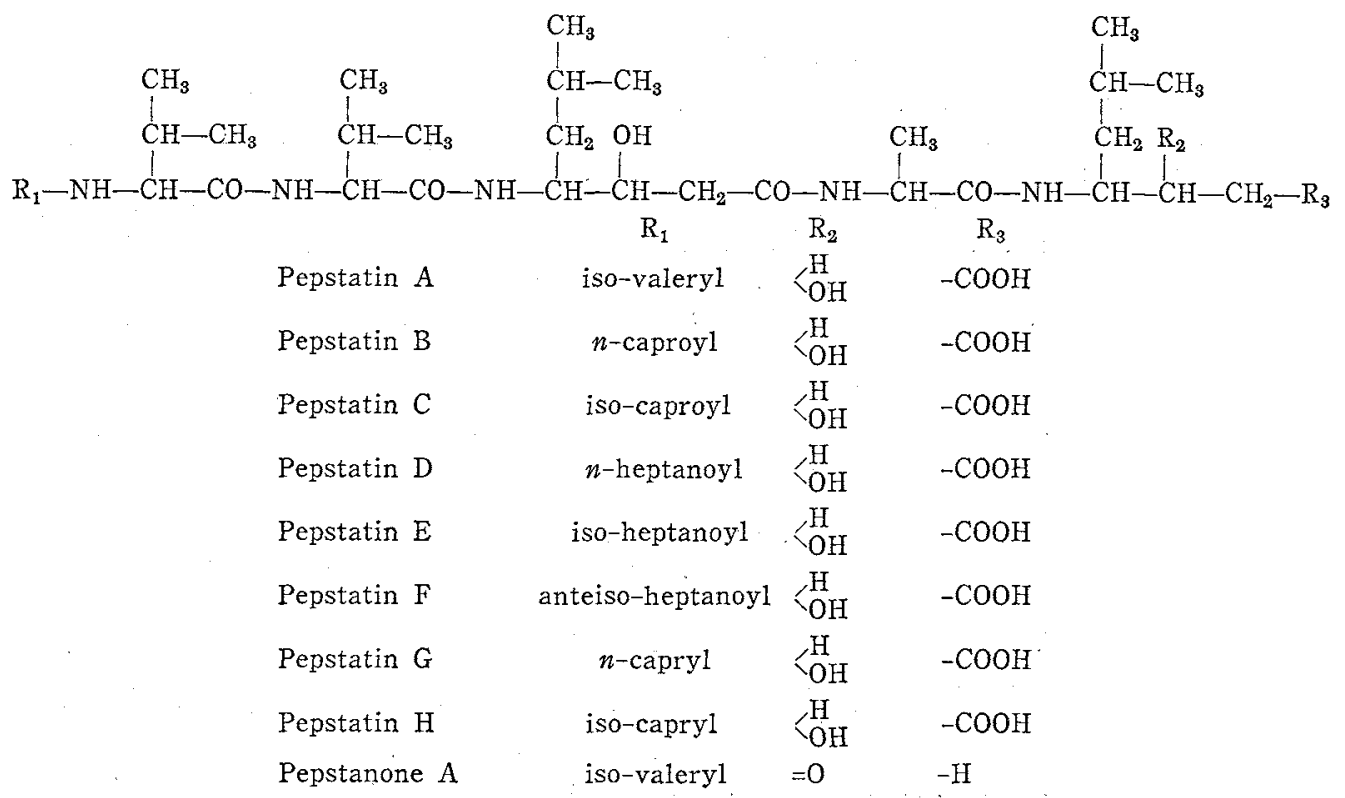

The activity of pepstatins and pepstanone $A$ in inhibiting pepsin, cathepsin $D$ and renin are shown in Table 2. Pepstatins $B, C, E$ and $G$ were equally active against pepsin as pepstatin $A$, but their activity against renin and cathepsin $\mathrm{D}$ was slightly greater. The activity of pepstatins against the latter enzymes depended on the number of carbon atoms in the fatty acid moiety, especially with renin. The larger the carbon number the stronger the activity. Pepstanone A in which the C-terminus was not carboxyl was equally or slightly less active against pepsin than pepstatin $A$. It indi-

Table 2. Biological activity of pepstatins

\begin{tabular}{l|c|c|c}
\hline & \multicolumn{3}{|c}{$\mathrm{ID}_{50}(\mu \mathrm{g} / \mathrm{ml})$} \\
\cline { 2 - 4 } & Pepsin & Renin & $\begin{array}{c}\text { Cathepsin } \\
\mathrm{D}\end{array}$ \\
\hline Pepstatin A & 0.01 & 4.5 & 0.011 \\
Pepstatin B & 0.01 & 3.0 & 0.0003 \\
Pepstatin F & 0.01 & 1.8 & 0.002 \\
Pepstatin G & 0.01 & 1.2 & 0.003 \\
Pepstanone A & 0.013 & 25 & - \\
\hline
\end{tabular}
cates that free carboxyl and hydroxyl groups in the G-terminal amino acid are not essential for the activity. However, as shown in Table 2, the activity of pepstanone A on the hydrolysis of nonapeptide by renin was about one-sixth that of pepstatin A, suggesting an involvement of the terminal carboxyl and hydroxyl groups in the inhibition of renin.

\section{Acknowledgement}

The authors wish to thank Misses K. YAmadA, M. NAmbo and F. KoJma for technical assistance throughout the course of study.

\section{References}

1) Umezawa, H.; T. Aoyagi, H. Morishima, M. Matsuzaki, M. Hamada \& T. Takguchi : Pepstatin, a new pepsin inhibitor produced by actinomycetes. J. Antibiotics $23: 259 \sim 262,1970$

2) Morishima, H.; T. TAKita, T. Aoy agt, T. TAKeuchi \& H. UmezaWa: The structure of pepstatin. J. Antibiotics $23: 263 \sim 265,1970$

3) Mryano, T.; M. Tomiyasu, H. Izuka, S. Tomisaka, T. Takita, T. Aoyagi \& H. Umezawa: New pepstatins, pepstatins $B$ and $C$, and pepstanone $A$, produced by streptomyces. J. Antibiotics $25: 489 \sim 491,1972$ 
4) Aoyagi, T.; S. Kunimoto. H. Morishima, T. Takeuchi \& H. Umezawa : Effect of pepstatin on acid proteases. J. Antibiotics $24: 687 \sim 694,1971$

5) Ikezawa, H.; T. AoyagI, T. TAKeuchi \& H. UmezaWa : Effect of protease inhibitors of actinomycetes on lysosomal peptidehydrolases from swine liver. J. Antibiotics $24: 488 \sim 490,1971$

6) Norman, P.S.: Studies of the plasmin system. I. Measurement of human and animal plasminogen. Measurement of an activator in human serum. J. Exptl. Med. 106:423 436, 1967

7) Anderson, G. W.; J.E. Zimmerman \& F.M. Caliahan: The use of esters of N-hydroxysuccinimide in peptide synthesis. J. Am. Chem. Soc. $86: 1839 \sim 1842,1964$

8) Morishima, H.; T. TAKita \& H. Umezawa: The chemical synthesis of pepstatin A. J. Antibiotics $25: 551 \sim 552,1972$

9) Stewart, J. M. \& J. D. Young: Solid phase peptide synthesis. Freeman, San Francisco, 1969

10) Schwyzer, R.; P. Steber \& H. Kappeler : Zur Syntheses von N-t-Butyloxycarbonyl-aminosäurer. Helv. Chim. Acta $42: 2622 \sim 2624,1959$

11) BRAY, G. A.: A simple efficient liquid scintillator for counting aqueous solutions in a liquid scintillation counter. Anal. Biochem. $1: 279 \sim 285,1960$

12) Kunimoto, S.; T. Aoyagi, H. Morishima, T. Takeuchi \& H. Umezawa : Mechanism of inhibition of pepsin by pepstatin. J. Antibiotics $25: 251 \sim 255,1972$

13) Lazar, J. \& S. W. Hoobler : Studies on the role of the adrenal in renin kinetics. Proc. Soc. Exptl. Biol. \& Med. $138: 614 \sim 618,1971$

14) Ontjes, D. A.; J. Majstoravich \& J. C. Roberts : Radiochemical assay for renin utilizing a synthetic insoluble substrate. Anal. Biochem. 45:374 384, 1972

15) Levine, M.; F. E. Dorer, J. R. Kahn, K. E. Lentz \& L. T. SkegGs : Chemical determination of hog kidney renin by an automated method. Anal. Biochem. $34: 366 \sim 375,1970$ 